\title{
Characterisation of the capsid protein gene from a nodavirus strain affecting the Atlantic halibut Hippoglossus hippoglossus and design of an optimal reverse-transcriptase polymerase chain reaction (RT-PCR) detection assay
}

\author{
Sindre Grotmol ${ }^{1, *}$, Audun H. Nerland ${ }^{1}$, Eirik Biering ${ }^{2}$, Geir K. Totland ${ }^{3}$, \\ Toyohiko Nishizawa ${ }^{4}$ \\ ${ }^{1}$ Institute of Marine Research, Department of Aquaculture, PO Box 1870, 5024 Bergen-Nordnes, Norway \\ ${ }^{2}$ Intervet Norbio AS, Thormahlensgt. 55, 5008 Bergen, Norway \\ ${ }^{3}$ University of Bergen, Institute of Zoology, Allégt. 41, 5007 Bergen, Norway \\ ${ }^{4}$ Faculty of Applied Biological Science, Hiroshima University, Kagamiyama 1-4-4, Higashihiroshima, 739, Japan
}

\begin{abstract}
A 1349 nucleotide fragment of the RNA2 from a nodavirus affecting Atlantic halibut Hippoglossus hippoglossus was characterised and the nuclotide sequence (accession no. AJ245641) was employed to develop an optimal reverse-transcriptase polymerase chain reaction (RT-PCR) detection assay. The sequenced part of the RNA2 of Atlantic halibut nodavirus (strain AH95NorA) was highly similar in organisation to that of the RNA2 of striped jack nervous necrosis virus (SJNNV), and comprised features common to all nodaviruses. These characteristics confirmed that the virus that causes viral encephalopathy and retinopathy (VER) in Atlantic halibut is a nodavirus. The nucleotide sequence of the 1349 nucleotide fragment of Atlantic halibut nodavirus RNA2 was $80 \%$ identical to the RNA.2 of SJNNV. The T2 region ( 830 nucleotides) of the RNA2 of Atlantic halibut nodavirus shared $98 \%$ of the nucleotide sequence when compared with the homologous region of barfin flounder nervous necrosis virus (BFNNV), while the nucleotide sequence identity to SJNNV in this region was $76 \%$. Phylogenetic analysis based on the nucleotide sequences of the T4 region (421 nucleotides) of Atlantic halibut nodavirus and of other fish nodaviruses revealed a close relationship to the nodaviruses of the barfin flounder clad that have been found in other cold-water species (Pacific cod Gadus macrocephalus and barfin flounder Verasper moseri). The nucleotide sequence of the RNA2 of Atlantic halibut nodavirus included some features that differ from that of SJNNV. The ORF of the RNA2 of Atlantic halibut nodavirus lacked 6 nucleotides through a single deletion and a 5-nucleotide deletion, separated by 4 nucleotides. The 3 '-non-encoding region contained a 21 nucleotide insert and a 3 nucleotide deletion when compared with SJNNV. In comparison with the RNA2 of SJNNV, the 3'-non-encoding region showed a nucleotide sequence identity of $84.5 \%$. A primer set based on the Atlantic halibut nodavirus nucleotide sequence was employed in order to design an optimal RT-PCR. The detection limit of the PCR was 10 to 100 copies of plasmid, while the detection limit of the RT-PCR assay was 100 to 1000 copies of in vitro transcribed viral RNA.
\end{abstract}

KEY WORDS: Fish nodavirus · Atlantic halibut $\cdot$ RNA2 $\cdot$ Capsid protein gene $\cdot$ RT-PCR

\section{INTRODUCTION}

The viruses of the Nodaviridae are pathogenic to insects and fish. Fish nodaviruses cause the disease

•E-mail: sindre.grotmol@imr.no viral encephalopathy and retinopathy (VER), also known as viral nervous necrosis (VNN), which affects a variety of farmed marine teleosts (Munday \& Nakai 1997) and often results in high mortality, particularly in the larval and juvenile stages. VER is charactensed by the high neurovirulence of the fish nodaviruses, and 
lesions comprised of cellular vacuolation and neuronal degeneration may be found in the brain, retina, spinal cord and ganglia.

Most of our knowledge of the structure and molecular biology of the Nodaviridae has been obtained from studies of viruses isolated from insects (for review see Schneeman et al. 1998). The virions are unenveloped and have icosahedral capsids with diameters ranging from 25 to $30 \mathrm{~nm}$. Their genomes consist of 2 molecules of messenger sense RNA, both of which are encapsidated in the same virion. RNA1 (3.1 kb) carries a gene that encodes the putative RNA-dependent RNA polymerase (Protein A). RNA2 $(1.4 \mathrm{~kb})$ contains a main open reading frame encoding the capsid protein precursor $\alpha$, which is cleaved to the capsid proteins $\beta$ and $\gamma$ during viral maturation in insect nodaviruses. In addition, a subgenomic transcript of RNA1, RNA3, which encodes a non-structural protein (Protein $B$ ), is present in the infected cell.

The nucleic acids and structural proteins of the nodaviruses affecting striped jack Pseudocaranx dentex (striped jack nervous necrosis virus [SJNNV]), European sea bass Dicentrarhcus labrax (D. labrax encephalitis virus [DIEV]) and barramundi $L$. calcarifer (Lates calcarifer encephalitis virus [ $L_{C} \mathrm{EV} \mid$ ) have been partially characterised (Mori et al. 1992, Comps et al. 1994) and these viruses belong to the Nodaviridae. The complete RNA2 of SJNNV and DIEV have been sequenced, and like insect nodaviruses they contain a main open reading frame that encodes the capsid protein (Nishizawa et al. 1995, Delsert et al. 1997). Although fish nodaviruses seem to be highly similar to insect nodaviruses in the organisation of genomic RNA and in other physical properties, the RNA2 of insect and fish nodaviruses share a low nucleotide sequence identity (Nishizawa et al. 1995, Delsert et al. 1997). Furthermore, capsid protein processing seems to differ between the groups, supporting the notion that fish nodaviruses possess unique features and constitute a group distinct from the insect nodaviruses (Delsert et al. 1997). Comparisons between the nucleotide sequences of a variable region (T4) of the viral capsid protein gene of more than 20 nodavirus strains showed that these may, according to this criterion, be divided into 4 major clads: the striped jack clad, the redspotted grouper clad, the tiger puffer clad and the barfin flounder clad (Nishizawa et al. 1997). The RNA2 of a nodavirus from European sea bass from the Mediterranean was found to have a sequence $99.5 \%$ identical to that of viruses of the redspotted grouper clad found in Japan (Sideris 1997), while a nodavirus affecting European sea bass from the Atlantic coast of France (Thiéry et al. 1999) could not be assigned to any of these clads. The significance of the genetic diversity among fish nodaviruses is unclear. Although it has been demon- strated that nodaviruses with distinct genomes may infect the same teleost species (Nishizawa et al. 1997. Thiéry et al. 1999), evidence of a restricted host range or adaptation to different temperature optima has been presented (Totland et al. 1999).

Since 1995, incidences of high mortality associated with a nodavirus-like agent have been reported from juvenile rearing facilities for Atlantic halibut Hippoglossus hippoglossus in Norway. The virus detected in Atlantic halibut is morphologically indistinguishable from other fish nodaviruses, and it cross-reacts with polyclonal antisera raised against SJNNV and DIEV (Grotmol et al. 1997). The primary aim of the present study was to further characterise the virus by investigating its genetic relationship to other fish nodaviruses by comparing the sequences of their capsid protein genes, and by characterising a recombinant partial capsid protein.

In diagnostic, epidemiologic and scientific work sensitive and reliable detection methods for nodavirus are essential. A reverse-transcriptase polymerase chain reaction (RT-PCR) (Nishizawa et al. 1994) has been designed to detect SJNNV, but this method has proved to be suboptimal for other nodavirus strains (Thiéry et al. 1999). In addition, it is possible to detect certain nodavirus strains by means of a fish cell line (SSN-1) derived from striped snakehead Channa striatus (Frerichs et al. 1996), but the Atlantic halibut nodavirus does not replicate efficiently in these cells (Grotmol unpubl. results). The second aim of our study was to utilise the RNA2 sequence acquired to develop a sensitive RT-PCR for detection of the nodavirus affecting Atlantic halibut, thus expanding the repertoire of diagnostic tools available.

\section{MATERIALS AND METHODS}

Virus source. Dead and moribund Atlantic halibut juveniles were collected from a commercial rearing facility in the western part of Norway during an outbreak of high acute mortality. The fish were stored at $-80^{\circ} \mathrm{C}$. Histopathological and immunohistochemical examination revealed lesions typical of VER as described by Grotmol et al. (1997). Eyes and brains were dissected free and used as source of viral RNA. The nodavirus strain from this outbreak was denoted AH95NorA. As a positive control, striped jack larvae infected with SJNNV strain SJ93Nag (Nishizawa et al. 1997) were utilised.

RT-PCR amplification and cloning. Total RNA was extracted from the brains and eyes of the Atlantic halibut and from whole striped jack larvae $(75 \mathrm{mg}$ of tissue) using Trizol ${ }^{\otimes}$ Reagent (Life Technologies, New York, USA) according to the protocol provided by the manufacturer. Target region 2 (T2) of the capsid pro- 


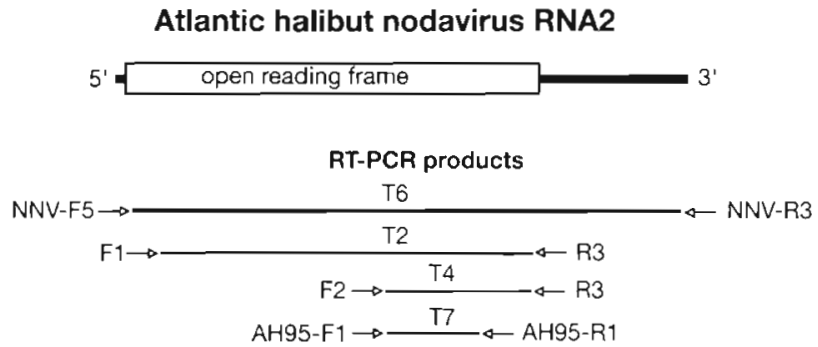

Fig. 1 Schematic map of the nodavirus RNA2, RT-PCR products and corresponding primers

tein genes (Fig. 1) of the 2 nodaviruses were amplified using an RNA-PCR kit (Perkin Elmer, CT, USA) as described by Nishizawa et al. (1994) using the modified primers F1 exp (5'-aaacatatg-GGATTTGGACGTGCGACCAA-3') and R3 exp (5'gctaagcttca-CGAGTCAACACGGGTGAAGA-3'). The sense primer F1 exp (nt 155-174) included 6 additional nucleotides as a linker composing the $N$ de I recognition site in addition to the initiation codon (atg), while the antisense primer, R3 exp, had 11 additional nucleotides of linker containing the Hind III recognition site and termination codon. Target region 6 (T6) (Fig. 1) was amplified using the sense primer VNN-F5 (5'-ATGGTACGCAAAGGTGA-3') and antisense primer VNN-R3 (5'GGCCATTTAACCACATG-3') (Nakai et al. 1995). The RTPCR procedure was performed as above with the exception of a higher concentration of $\mathrm{MgCl}_{2}(2.5 \mathrm{mM})$ and an annealing temperature of $50^{\circ} \mathrm{C}$. The amplified products were analysed by $1.5 \%$ agarose gel electrophoresis. The T2 and T6 regions were cloned into the pCR-Script SK(+) vector using the pCR-Script cloning kit (Stratagene Inc., CA, USA) utilising the manufacturer's protocol, and the plasmids were denoted pAHT6 and pAHT2, respectively.

Sequence determination. The cloned PCR products were sequenced by means of the $\mathrm{ABI}$ dye primer cycle sequencing kit (Perkin Elmer), an automatic thermal cycler and the ABI auto sequencer A737-36, used according to the manufacturer's recommended procedures. The sequences were obtained by sequencing serveral cDNA clones in both directions according to standard procedures and the sequences were assembled and analysed with the Mac Dnasis program (Hitachi Software Engineering, CA, USA).

Sequence alignment and phylogenetic analysis. The sequence of the T2 region was compared with previously published homologous sequences of SJNNV, the tiger puffer nervous necrosis virus (TPNNV), redspotted grouper nervous necrosis virus (RGNNV) and barfin flounder nervous necrosis virus (BFNNV) (Nishizawa et al. 1995). A dendrogram based on the T4 sequence (Fig. 1) of the nodavirus from Atlantic halibut and the T4 sequences of 25 other fish nodaviruses (Nishizawa et al. 1997) was generated using the Clustral W (Thompson et al. 1994) and the TreeView (Roderic 1996) computer programs.

Design of RT-PCR detection. Based on the sequence of the RNA2 from AH95NorA, new primers were designed using the VectorNTI software (InforMax, Bethesda, USA). These primers, designated AH95-F1 (5'-AGTGCTGTGTCGCTGGAGTG-3') and AH95-R1 (5'-CGCCCTGTGTGAATGTTTTG-3'), generate a PCR fragment of $341 \mathrm{bp}$ (T7) (Fig. 1). The PCR Optimisation Kit from Boehringer Mannheim (Ingelheim, Germany) was used to optimise the reaction regarding $\mathrm{MgCl}_{2}$ concentration and $\mathrm{pH}$. The result was the following procedure for the RT reaction: $1 \mu \mathrm{l}$ of RNA isolated by the TriZol method described above was added to $9 \mu \mathrm{RT}$-reaction mix containing (final concentrations) $50 \mathrm{mM} \mathrm{KCl}, 10 \mathrm{mM}$ Tris- $\mathrm{HCl}(\mathrm{pH} \mathrm{8.3),} 5 \mathrm{mM} \mathrm{MgCl}$, $10 \mu \mathrm{M}$ Random Hexamer primers (Perkin Elmer), $2 \mathrm{mM}$ each of dATP, dCTP, dGTP, dTTP, 1 unit RNase inhibitor (Perkin Elmer) and 2.5 units MuLV RT (Perkin Elmer). The mixture was incubated at $22^{\circ} \mathrm{C}$ for $10 \mathrm{~min}$, at $42^{\circ} \mathrm{C}$ for $5 \mathrm{~min}$, and finally at $95^{\circ} \mathrm{C}$ for $10 \mathrm{~min}$.

For the PCR, $10 \mu$ l of the RT reaction fluid was added to $40 \mu \mathrm{PCR}$ reaction mix containing $50 \mathrm{mM} \mathrm{KCl}$, $10 \mathrm{mM}$ Tris- $\mathrm{HCl}(\mathrm{pH} 8.3$ ), $1.25 \mathrm{mM} \mathrm{MgCl}, 0.25 \mu \mathrm{M}$ of each of the primers AH95-F1/AH95-R1, and 1.25 units AmpliTaq DNA polymerase (Perkin Elmer). The mixture was heated to $95^{\circ} \mathrm{C}$ for 2 min, and then submitted to 30 cycles each of $50 \mathrm{~s}$ at 95,56 and $72^{\circ} \mathrm{C}$, respectively. Finally, the reaction was heated to $72^{\circ} \mathrm{C}$ for 5 min and then cooled to $4^{\circ} \mathrm{C}$. An aliquot of $7 \mu$ of the reaction volume was added to sample buffer and run on a $1 \%$ agarose gel in TBE buffer using standard methods (Sambrook et al. 1989).

Sensitivity of the PCR amplification. From a starting concentration of $1 \mu \mathrm{g} \mathrm{Hl}^{-1}$, the plasmid pAHT6 was 10 fold serial diluted. Samples containing from $10^{10}$ to less than 1 copy of the plasmid molecule were subjected to PCR, employing similar conditions as for the RT-PCR described above. Samples of $7 \mu \mathrm{l}$ of the $50 \mu$ reaction volumes were then subjected to $1 \%$ agarose gel electrophoresis in TBE buffer.

In vitro transcription of viral RNA. The plasmid pAHT6 was linearised by Bgl II digestion (Fig. 2) and purified by means of a Qiaquick Nucleotide Removal kit (Qiagen, Basel, Switzerland). RNA was in vitro transcribed using $T 7$ polymerase and the RiboMAX Large Scale Production System from Promega (Madison, WI, USA) according to the procedure supplied by the manufacturer, except that the RNA at the final step was purified using TriZol. The RNA was treated with DNase and the presence of template DNA was controlled by PCR. The concentration of RNA was determined by measuring the optical density at $260 \mathrm{~nm}$ 
SJOri

AH 95 NOrA

sJori

AH95NOTA

SJOri

AH 95 NOrA

SJOri

AH 95 NorA

SJOri

AH95Nora

SJOri

AH 95 NOrA

SJOri

AH 95 Nor A

SJOri

AH 95 NOrA

SJOri

A. 95 NOI A

SuOri

A H 95 NOYA

SJOri

A.H 95 Nor A

SJori

A.H $95 \mathrm{Nor} A$

SJOri

A.H 95 NorA

SJOri

A.H 95 NOrA

SJOri

AH95NOKA
(1) CGCTTTGCAAGTCAAAATGGACGCAAAGGTGATAAGAAATTGCAAAAC MetVal. ArgLysGIyAspLysLysLeuAlaLysP
(51) CCCCGACCACAAAGGCCGCCAATTCTCAACCACGTCGACGTGCAACACAG roProThrThrLysAlaA laAsnSerG]nProArgArgArgAlaThrGln

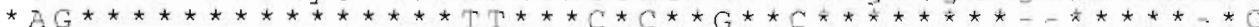
*Ala * * * *Val * Pro * * * * * Asr - Asn

(101) CGCCGTCGCAGTGG- - TAGGGCTGATGCACCCTTAGCTAAGGCATCGAC ArgArgArgsergly - ArgAiaAspala ProleuAlalysaláserth

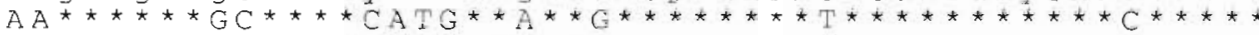
$\mathrm{Asn} * \quad * \operatorname{Arg} * \mathrm{M}$ et

(1 4 8) TATCACGGGATTTGACGTGCGACCAATGATGTCCATATCTCGGGAATT rI I ThrGlypheGIyArgAIaThrAsnASpValHisIleserGIyMet.

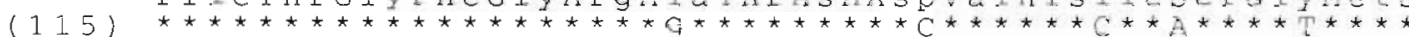

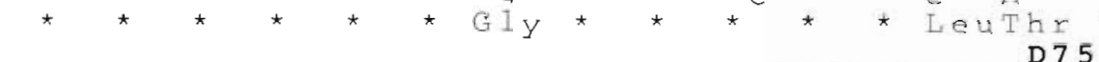

(198) CACGGATCGCTCAAGCAGTTGTTCCAGCCGGGACAGGAACAGATGGAAG erArgIleAlaGlnAlaval.ValproAlaGlyThrGlyThrAspGIyLys $\star \mathrm{GA} * \mathrm{~A} * \star \star \star *$

ATTGTCGTCGATTCCACAATCGTTCCAGAACTCCTGCCACGGCTTGGACA I leValvalAspserThrI leVaiprogl. LeuLeuproArgLeuGlyHi

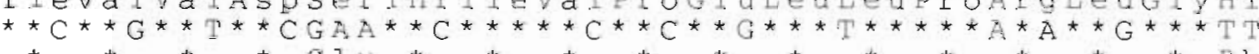

(298) CGCTGCTCGAATCTTCCAGCGATACGCTGTTGAAACACTGGAGTTCGAAA sAlaAlaArgIlePheGlnArgTyralavalgluThrLeuglupheGluI

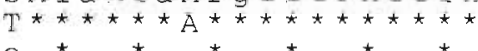

TTCAGCCAATGTGCCCCGCAAACACGGGCGGTGGT TACGTTGCTGGCTTC leGInPrometCysProAlaAsnThrGIYGIyGlyTyrValAlaGlyPhe

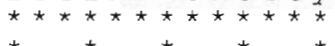

CIGCCTGATCCAACTGACAACGACCACACCTTCGATGCGCTCCAAGCAAC LeuProAspProThrAspAsnAspHisThrpheAspAlateuGlnAlaTh

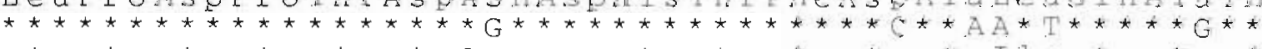

(448) TCGTGGTGCAGTCGTCGCCAAATGGTGGGAAAGTCGAACAGTCCGGCCCC rArgGIYAlaValValAla. LySTrpTrpGluserArgThrValArgProG

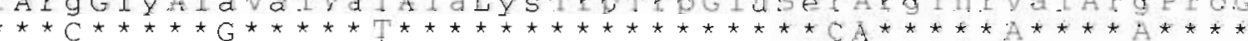

(498) AGTATACTCGAACGCTTCTCTGGACCTCAACCGGGAAGGAGCAGCGATTG InTyrThrArgThrLeuLeuTrpThrserThrGIyLySGIUGInArgLeu

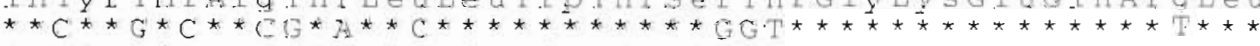

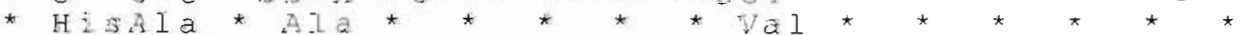

(515) ACATCCCCGGGCCGGTTGGTACTCCTGTGTGCCGGCAACAACACTGACGT

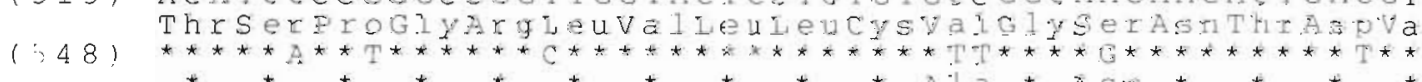

(598) TGTCAACGTGTCAGTCATGTGTCGCTGGAGCGTTCGCCTTAGTGTCCCGT

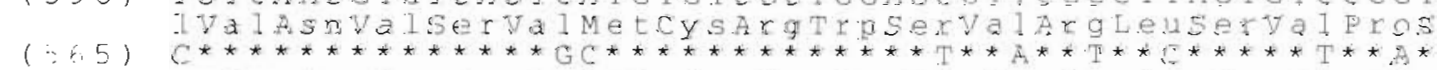

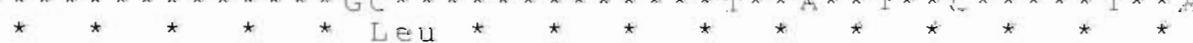

(648) CCCTTGAGACACCTGAGGACACCACCGCTCCAATTACTACCCAGGCGCCA

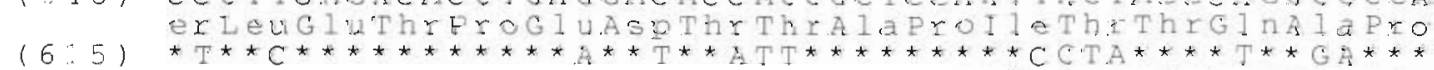

(698) CTCCACA.ACGATTCCATTAACAACGGTTACACTGGATTTCGTTCCATTCT LeUHisAsnAspSerIIeAsnAsnGIYTyrThrGlypheArgSerIleLe

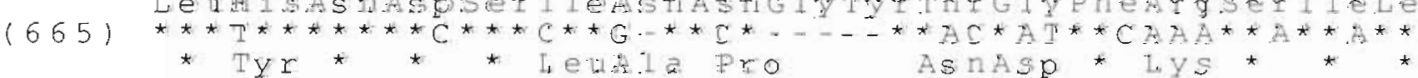


SJOri

$(748)$

AH $95 \mathrm{NOSA}$

$(709)$

SUOri

$(798)$

AH 95 NorA

$(758)$

SUOri

$(847)$

AH 95 NorA

$(808)$

SJOri

(897)

AH9 5 NOr A

$(858)$

SJOTi

$(947)$

AH 95 NOrA

(908)

SuOri

$(997)$

AH 95 NorA

(958)

SJOri

AH95NorA

SuOri

AH 95 NorA

SJOri.

AH 95 NorA

SJOri

AH 95 NOYA

S J Ori

AH 95 NorA

SJOri

AH $95 \mathrm{~N}$ or $\mathrm{A}$

SJOri.

AH 95 Nor A

SJOri

AH 95 NOY A
CTTGGGCTCGACCCAACTCGACCTCGCTCCTGCAAACGCTGTCTTTGTCA uLeuGlyserThrGlnLeuAspLeuAlaProAla AsnA I a val PheVal t

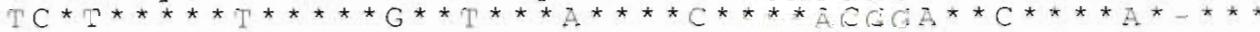

CT-GACAAACCGTTGCCCATTGATTACAATCTTGGAGTGGGCGACGTCGA hr AsplysProLeuProIleAsoTyrasnLeuglyvalGiyAspValAs

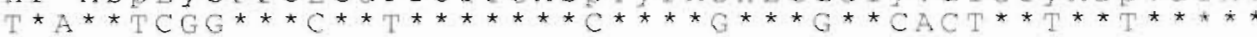
Leu * Arg * * Ser * * * Ser*** Thr * * *

CCGGGCCGTGTACTGGCACCTGCAGAACAAAGCTGGAGACACTCAGGTAC oArgA laval TyrTrpHisLeuGlnLVsLysAlaGlyAspThrGlnValp

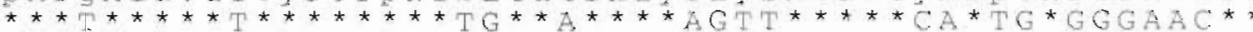
******Vallys * Val* * AsnAlaGiyThr

CTGCTGGGTACTT TGACTGGGGACTGTGGGATGACTT TACAAGACATTC roAlaGly TyrPheAspTrpGlyLeuTrpAspAspPheAsnLysThrPhe

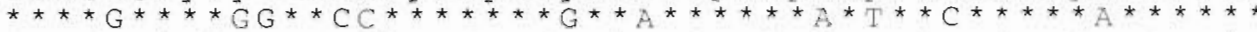

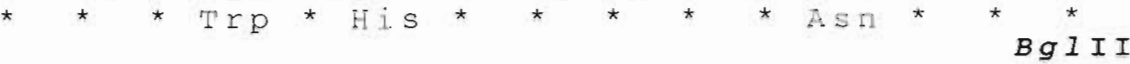

ACAGTTGGGGCGCCCTACTACTCCGACCAGCAACCACGGCAAATCTTGCT ThrValGlyAlaProTyrTyrserAspGInGInProArgGlnIleLeuLe

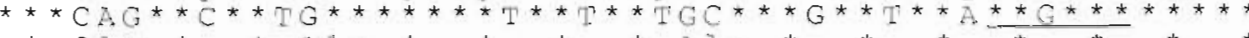
* GIn* * A I a * * * A I a

GCCGGCTGGCACGCTCTTCACCCGTGTTGACTCGGAAAACTAACCGGGTC uProAlagly'ThLeuPheThxArgValAspsergluAsn***

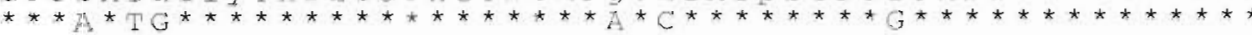
$* \operatorname{Val} * * * * *$ A $*$ A a $* * * * *$

ATCCGGATCCCTAGTGCGTATCGTGGATGACCAATTCGAGAAATTGATTA

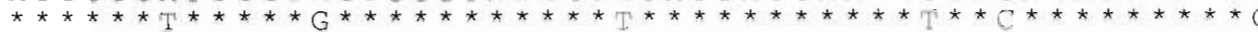

CGGCACTAACCACTAT .......................AA A T TAAAT T

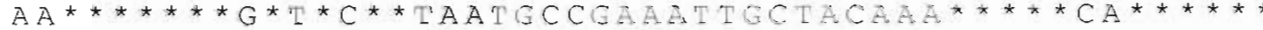

Fig. 2. (above and facing page) Alignment of the cDNA nucleotide sequence and the deduced amino acid sequence of the RNA2 from the nodavirus strains SJOri (Nishizawa et al. 1995) and AH95NorA constructed by the Clustral W program. ${ }^{*}$ Nucleotides or amino acids identical to those in the same positions in SJOri. (-) Nucleotide gaps. Asp75 (D75) is in bold and represents a catalytic residue conserved among all nodaviruses. Two stretches of Arg residues also common to all nodaviruses are underlined and in bold, and are assumed to participate in the binding of the genomic RNA to the internal capsid wall. The Bgl II site where the in vitro RNA transcription terminated is indicated and underlined. The Genbank accession number is AJ245641

and the number of RNA molecules $\mathrm{ml}^{-1}$ was calculated. The RNA was stored in TE buffer $(\mathrm{pH} \mathrm{8.0)}$ at $-80^{\circ} \mathrm{C}$.

Sensitivity of the RT-PCR assay. Ten-fold dilutions of in vitro transcribed RNA, starting with $10^{8}$ copies of RNA molecules sample ${ }^{-1}$, were subjected to the RTPCR amplification as described above. Random primers were used for the RT reaction and AH95-F1/AH95-R1 for the PCR amplification. Samples of $7 \mu \mathrm{l}$ of the $50 \mu \mathrm{l}$ reaction volumes were subjected to $1 \%$ agarose gel electrophoresis in TBE buffer

Expression of recombinant $\mathrm{T} 2$ protein. The T2 insert of the pAH95T2 was exerted by applying Nde I and Hind III restriction enzymes with recognition sites in the linker sequences of the forward and reverse PCR primers. T2 exerts were ligated into an expression vector 
plasmid, pET-25b (+) (Novagen, WI, USA), using the DNA Ligation High Kit (Toyobo, Osaka, Japan) according to the manufacturer's instructions. The resulting plasmid construct was denoted pAHT2 exp. The plasmid was used to transform Escherichia coli (BL21) and clones containing the expression plasmid with the partial capsid protein gene ORF (T2 region) were cultured in LB medium ( $1 \%$ Bacto-tryptone, $0.5 \%$ Bacto-yeast extract, $1 \% \mathrm{NaCl}_{1} \mathrm{pH} 7.4$ ) with $50 \mu \mathrm{g} \mathrm{ml}^{-1}$ ampicillin. The cells were induced by resuspension in fresh LB medium containing $50 \mu \mathrm{g} \mathrm{ml}^{-1}$ ampicillin and $1 \mathrm{mM}$ isopropylthio $\beta$-D-galactoside (IPTG). Following incubation at $37^{\circ} \mathrm{C}$ for $3 \mathrm{~h}$, the cells were washed and resuspended in $50 \mathrm{mM}$ Tris-HCl (pH 8.0) - 2mM EDTA solution. After addition to $100 \mu \mathrm{g} \mathrm{ml}^{-1}$ lysozyme and $0.1 \%(\mathrm{~V} / \mathrm{V})$ Triton X-100, the cell suspension was incubated at $30^{\circ} \mathrm{C}$ for $15 \mathrm{~min}$ and then sonicated until the solution lost its viscosity. The insoluble fraction containing the induced T2 expression protein was washed twice by centrifugation $(12000 \times g$, $15 \mathrm{~min}, 4^{\circ} \mathrm{C}$ ) and resuspended into $50 \mathrm{mM}$ Tris- $\mathrm{HCl}$ (pH 8.0) - 2mM EDTA solution.

SDS-polyacrylamide gel electrophoresis (SDS-PAGE) and Western blot. The insoluble protein fraction from the induced BL21 cells and uninduced controls was submitted to SDS-PAGE (12\% gel) under the reducing conditions of Laemmli (1970) and the relative amount of recombinant protein from both SJ93Nag and AH95NorA was analysed by gel scanning and the Molecular Analysis Software (Bio-Rad, CA, USA), and found to be nearly identical. The Western blot was performed by electroblotting the proteins to nitrocellulose membranes as described by Towbin et al. (1979). The membranes were incubated at room temperature for $2 \mathrm{~h}$ with a polyclonal rabbit antiserum against SJNNV and positive protein bands were visualised by alkaline phosphataseconjugated antibodies, bromochloroindolyl phosphate (X-phosphate) and nitroblue tetrazolium (NBT).

\section{RESULTS}

\section{Nucleotide sequence}

The sequenced fragment of the RNA2 from the Atlantic halibut nodavirus (strain AH95NorA) was highly similar in organisation to that of the SJNNV RNA2, and seemed to contain 1 main open reading frame (ORF) (Figs. $1 \& 2$ ). Comparison with the nucleotide sequence of the 1349 base fragment from the Atlantic halibut nodavirus indicated an $80 \%$ identity to the nucleotide sequence of the RNA2 of the SJNNV (strain SJOri, Nishizawa et al. 1996) (Fig. 2). In the ORF a nucleotide sequence identity of $78.7 \%$ to SJOri was found. In the deduced amino acid sequence an aspartic acid residue in position 75 (D75) that is common to all nodaviruses was identified (Fig. 2). This residue represents part of a catalytic site which is involved in capsid protein cleavage in insect nodaviruses. Two stretches of arginine residues common to all nodaviruses were also identified. These basic residues are assumed to participate in the binding of the genomic RNA to the internal capsid wall. Adjacent to these arginines a number of other negatively charged amino acid residues were present. The nucleotide sequence of the RNA2 of Atlantic halibut nodavirus contained a number of features that differ from that of SJOri. From nucleotide 716 (referring to SJOri, Fig. 2), the Atlantic halibut nodavirus lacked 6 nucleotides, consisting of a single deletion and a 5 -nucleotide deletion, separated by 4 nucleotides (Fig. 2). In the codons between nucleotide 225 and nucleatide 260, 11 out of 12 codons had base substitutions in the third position which resulted in only 1 alteration in the amino acid sequence. The 3 '-non-encoding region contained an additional 21 nucleotides from position 1112 and a 3-nucleotide deletion from position 1255 when compared to SJOri. In comparison with the RNA2 of SJOri the 3'-non-encoding region showed a nucleotide sequence identity of $84.5 \%$.

The T2 region (830 nucleotides) of the Atlantic halibut nodavirus RNA2 had a nucleotide sequence that was practically identical $(98.4 \%)$ to that of the T2 region of the BFNNV, while the nucleotide sequence identity to the SJNNV in this region was $76 \%$ (Table 1). When the T4 region (421 nucleotides) of the Atlantic halibut nodavirus was compared with 25 other nodavirus strains, the nucleotide sequence identity ranged from 66 to $98 \%$, while the identity in the deduced amino acid sequence ranged from 70 to $97 \%$ (Table 2). The T4 nucleotide sequence from the Atlantic halibut strain showed identities of 97.9 and $98.2 \%$ to nodavirus strains from barfin flounder and Pacific cod, respectively, while the identity to the strains of the striped jack group was approximately $66 \%$ (Table 2). In the molecular dendrogram the Atlantic halibut nodavirus formed a clad together with the nodaviruses from barfin flounder and Pacific cod (Fig. 3).

Table 1. Nucleotide and amino acid sequence similarities of the $\mathrm{T} 2$ region of the Atlantic halibut nodavirus (AH95Nor A) and nodavirus strains from other teleosts (data from Nishizawa et al. 1995). (SJNNV = striped jack nervous necrosis virus; $\mathrm{TP}=$ tiger puffer; $\mathrm{BF}=$ barfin flounder $; \mathrm{JF}=$ Japanese flounder; $R G=$ red spotted grouper)

\begin{tabular}{|lcc|}
\hline & \multicolumn{2}{c|}{ AH95NorA } \\
& Nucleotide level & Amino acid level \\
\hline SJNNV & 75.51 & 88.85 \\
TPNNV & 75.96 & 89.57 \\
BFNNV & 98.43 & 98.55 \\
JFNNV & 82.77 & 95.65 \\
RGNNV & 82.29 & 95.65 \\
\hline
\end{tabular}


Table 2. Nucleotide and predicted amino acid sequence identity of the T4 region of the Atlantic halibut nodavirus to other fish nodaviruses (data from Nishizawa et al. 1997). The different nodavirus strains are shown in the same order as in Fig. 3 from top to bottom

\begin{tabular}{|c|c|c|c|}
\hline \multirow{2}{*}{$\begin{array}{l}\text { Virus } \\
\text { strain }\end{array}$} & \multirow[t]{2}{*}{ Source } & \multicolumn{2}{|c|}{ Sequence identity (\%) to AH95NorA at: } \\
\hline & & Nucleotide level & Amino acid level \\
\hline TP93Kag & Tiger puffer Takifugu rubripes (Japan) & 68.7 & 73.4 \\
\hline JF95Hok & Japanese flounder Paralichthys olivaceus (Japan) & 68.7 & 71.9 \\
\hline SJOri & Striped jack Pseudocaranx dentex (Japan) & 66.7 & 71.1 \\
\hline SJ91Nag & Striped jack Pseudocaranx dentex (Japan) & 66.4 & 71.1 \\
\hline RS95Hir & Red sea bream Pargus major (Japan) & 66.1 & 70.3 \\
\hline SJ92Nag & Striped jack Pseudocaranx dentex (Japan) & 66.1 & 70.3 \\
\hline SJ93Nag & Striped jack Pseudocaranx dentex (Japan) & 66.1 & 70.3 \\
\hline SJ94Nag & Striped jack Pseudocaranx dentex (Japan) & 66.1 & 70.3 \\
\hline BF93Hok & Barfin flounder Verasper moseri (Japan) & 97.9 & 96.0 \\
\hline PC96Hok & Pacific cod Gadus macrocephalus (Japan) & 98.2 & 96.8 \\
\hline Ba94Aus & Barramundi Lates calcarifer (Australia) & 74.5 & 84.1 \\
\hline JF93Hir & Japanese flounder Paralichthys olivaceus (Japan) & 75.9 & 85.7 \\
\hline MR94Tha & Malabar reef cod Epinephelus malabaricus (Thailand) & 75.3 & 86.5 \\
\hline RG94Oka & Redspotted grouper Epinephelus akaara (Japan) & 76.9 & 86.5 \\
\hline JF94Wak & Japanese flounder Paralichthys olivaceus (Japan) & 76.9 & 86.5 \\
\hline JF95Oit & Japanese flounder Paralichthys olivaceus (Japan) & 76.9 & 86.5 \\
\hline RG91Tok & Redspotted grouper Epinephelus akaara (Japan) & 76.9 & 86.5 \\
\hline SB95Ita & Sea bass Dicentrarchus labrax (Italy) & 76.6 & 85.7 \\
\hline Umb95Ita & Umbrina Umbrina sp. (Italy) & 76.9 & 86.5 \\
\hline SG94Oit & Sevenband grouper Epinephelus septemfasciatus (Japan) & 76.9 & 85.7 \\
\hline JF95Tok & Japanese flounder Paralichthys olivaceus (Japan) & 76.9 & 85.7 \\
\hline KG95Oit & Kelp grouper Epinephelus moara (Japan) & 77.7 & 86.5 \\
\hline JF95Sag & Japanese flounder Paralichthys olivaceus (Japan) & 77.2 & 86.5 \\
\hline PA940it & Purplish amberjack Seriola dumerili (Japan) & 77.4 & 86.5 \\
\hline JS95Shi & Japanese sea perch Lateolabrax japonicus (Japan) & 77.2 & 86.5 \\
\hline
\end{tabular}

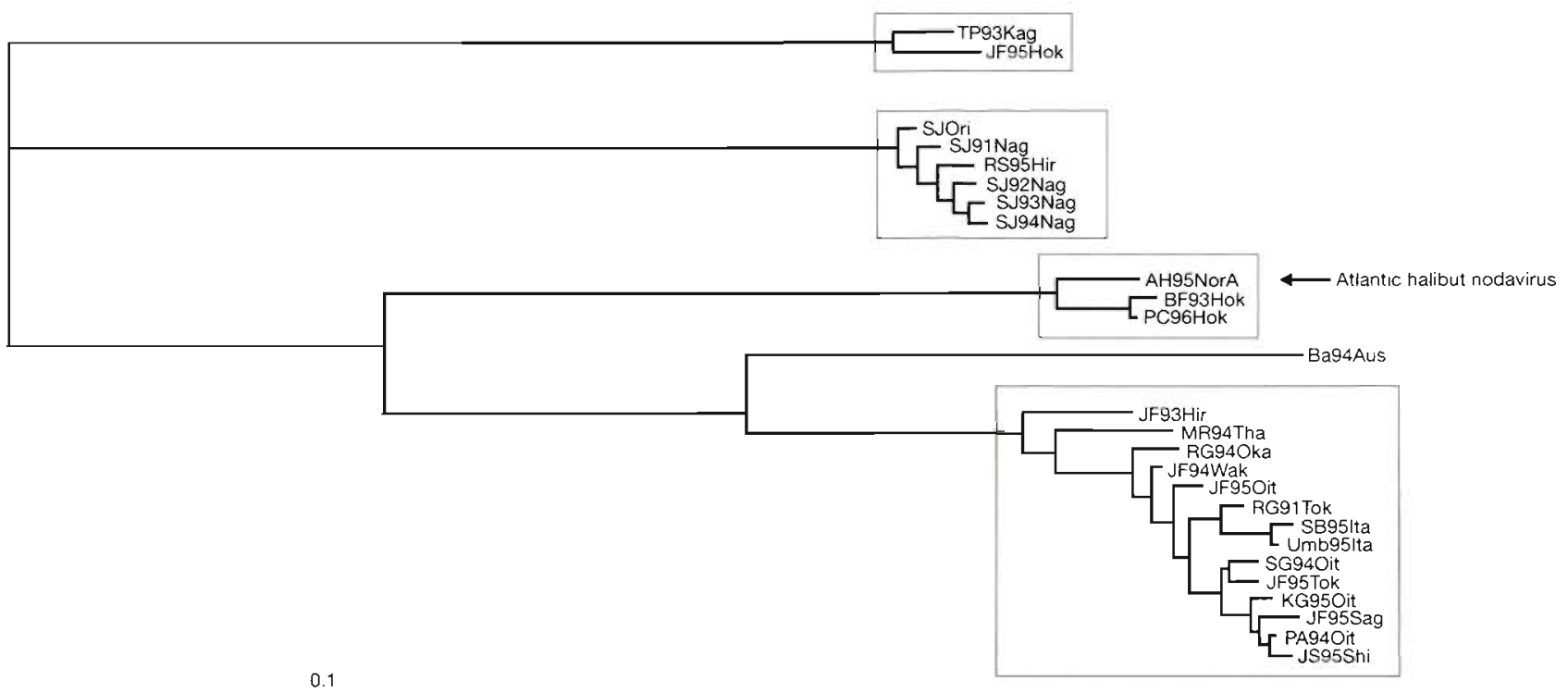

Fig. 3. The molecular dendrogram deduced from analysis of the T4 nucleotide sequence of 26 fish nodavirus strains based on data from Nishizawa et al. (1997). The dendrogram was built by the neighbour joint criteria with the Clustral W and TreeView 1.0 programs. The lengths of horizontal branches are proportional to the number of nucleotide substitutions, and the scale bar length indicates 0.1 nucleotide replacements site ${ }^{-1}$. Boxes indicate the major clads. From above: tiger puffer clad, striped jack clad, barfin flounder clad and red-spotted grouper clad. Note the Atlantic halibut nodavirus in the clad with strains from the barfin 


\section{RT-PCR detection assay}

Serial dilution of the plasmid pAHT6 showed that 10 to 100 copies sample ${ }^{-1}$ could be detected by the PCR amplification (Fig. 4A). Agarose gel electrophoresis of in vitro transcribed viral RNA revealed 1 major band with the expected molecular weight (Fig. 4B). Serial dilution of the in vitro transcribed viral RNA revealed that the lower detection limit of the RT-PCR detection assay was 100 to 1000 RNA copies sample ${ }^{-1}$ (Fig. 4C)

\section{SDS-PAGE and Western blot}

SDS-PAGE analysis showed that the expression proteins from the T2 region of both the Atlantic halibut and the SJNNV (SJ93Nag) had a molecular mass of approximately $32 \mathrm{kDa}$ (Fig. 5A). In Western blotting the anti-SJNNV serum reacted with the striped jack virus $\mathrm{T} 2$ expression protein and showed a weaker cross-reaction with the Atlantic halibut virus T2 expression protein (Fig. 5B). Uninduced controls did not react in the Western blot (data not shown).

\section{DISCUSSION}

\section{Sequence analysis}

Viral encephalopathy and retinopathy (VER) in larval and juvenile Atlantic halibut associated with a nodavirus-like agent has been reported previously
(Grotmol et al. 1997, 1999). The significant level of nucleotide sequence identity between the RNA2 of the Atlantic halibut nodavirus and SJNNV confirms that these virus strains are closely related and that the causative agent of VER in the Atlantic halibut, as in other teleost species (Nishizawa et al. 1995, 1997, Delsert et al 1997, Munday \& Nakai 1997, Sideris 1997. Thiéry et al. 1999) is a nodavirus.

Phylogenetic analysis based on the nucleotide sequence of the T4 region, which has high nucleotide sequence variability between strains, indicates that the Atlantic halibut nodavirus is closely related to the nodaviruses of the barfin flounder clad (Nishizawa et al. 1997). This clad comprises nodaviruses found in Pacific cod Gadus macrocephalus and barfin flounder Verasper moseri, which are also cold-water species. The nodaviruses within this clad are found in Pacific and Atlantic Oceans, respectively. One possible explanation of this phenomenon is that the nodavirus strains that belong to the barfin flounder clad may be adapted to replication at low temperature through selection and may have spread naturally among cold-water species in the oceans of the northern hemisphere. Alternatively, the nodavirus may have moved from the Pacific to the Atlantic Ocean or vice versa in the process of fish exports or through other human activities. Although it cannot be excluded, it is not probable that the BFNNV and AH95NorA, which have nearly identical nucleotide sequences $(98.4 \%$ ) in the T2 region, have evolved independently in Japan and Norway. Further characterisation of the complete genomes and mutation rates, but also possible host ranges or temperature adapta-
A

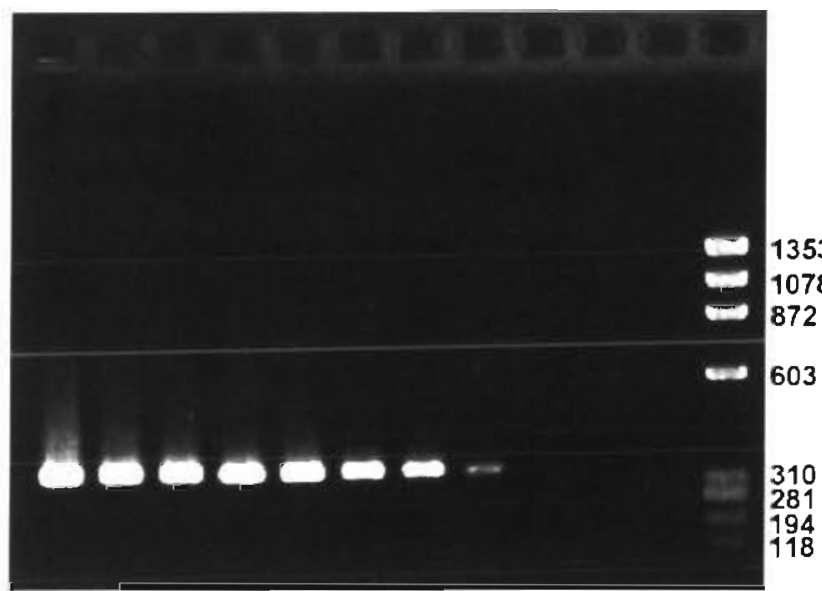

$\begin{array}{lllllll}3 & 4 & 5 & 6 & 7 & 8 & 9\end{array}$

M bp

\section{B}

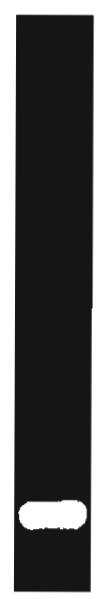

1234567
C

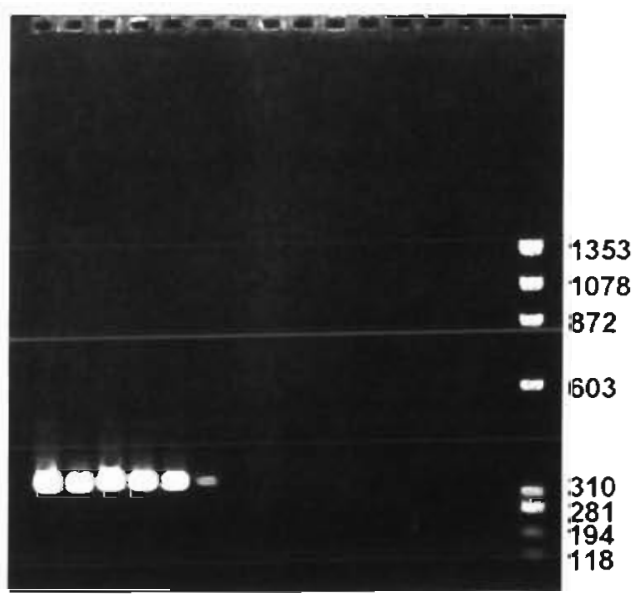

M bp

Fig. 4. Agarose gel electrophoresis. (A) Sensitivity of PCR using serial dilutions of the plasmid pAHT6 as template. The number of plasmid copies per reaction for each lane was as follows: (1) $10^{10}$, (2) $10^{9}$, (3) $10^{8}$, (4) $10^{7},(5) 10^{6},(6): 10^{5},(7) 10^{4},(8) 10^{3},(9) 10^{2} \mathrm{M}$ DNA marker $\phi \times 174$ Hae III. (B) In vitro transcribed viral RNA. (C) Sensitivity of the RT-PCR assay using in vitro transcribed viral RNA as template. The number of RNA copies per reaction for each lane was as follows: (1) $10^{8}$, (2) $10^{7}$, (3) $10^{6}$, (4) $10^{5}$. (5) $10^{4}$, (6) $10^{3},(7) 10^{2}$. M: DNA marker $\phi \times 174$ Hae III 


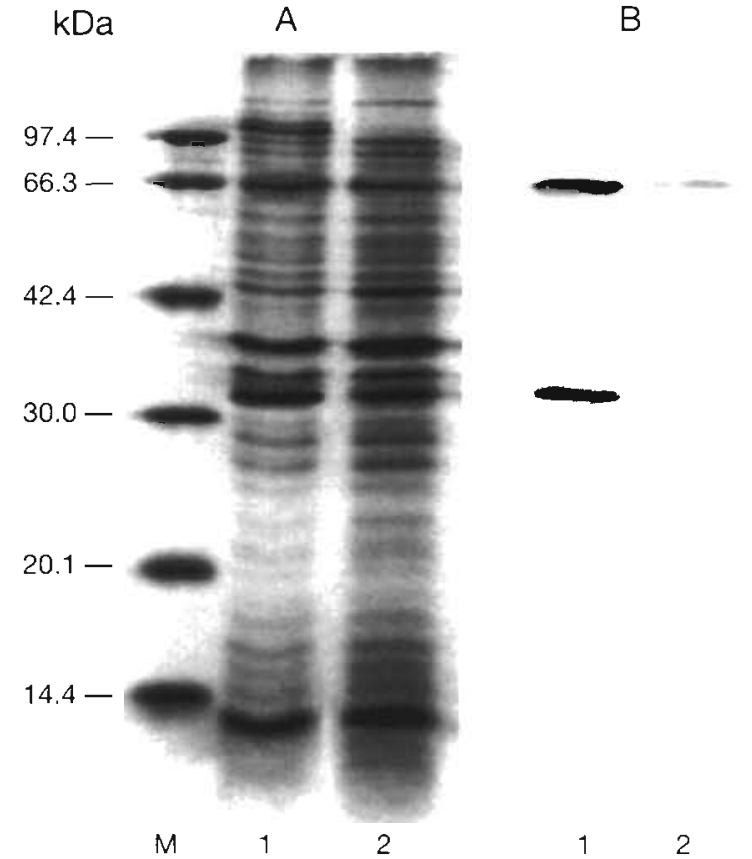

Fig. 5. (A) $12 \%$ SDS-polyacrylamide gel stained with Coomassy brilliant blue (CBB). (B) Western blot using anti-SJNNV rabbit serum. $M$ : molecular size marker, 1: expressed T2 protein of SJNNV, 2: expressed T2 protein of Atlantic halibut nodavirus. Note the 2 bands in the Western blot, which probably represent a monomer and a dimer form of the T2 expression proteins

tions of the fish nodaviruses is necessary for a more thorough understanding of their relationship and epidemiologies.

As in the SJNNV, the RNA2 of Atlantic halibut nodavirus possesses a long 3 '-non-encoding tail which, when compared to the sequence of the SJOri, is conserved and may imply an important functional or structural role of this region in fish nodaviruses.

\section{RT-PCR assay}

At present nodaviruses may be detected using RTPCR (Nishizawa et al. 1994, Thiéry et al. 1999), immunological methods such as immunohistochemistry (Grotmol et al. 1999) or ELISA (Arimoto et al. 1992) and the striped snake head (SSN-1) cell line (Frerichs et al. 1996). The latter method may detect some nodavirus strains, but the Atlantic halibut nodavirus, for instance, does not replicate efficiently in these cells (Grotmol unpubl. results). The detection of viral genomes using RT-PCR may be hampered by the high degree of specificity of the method. The presence of sequence variation within fish nodaviruses may result in mismatches between the primers and the sequences of their putative binding sites, causing variation in sensitivity or even failure of detection (Nishizawa et al. 1996, Thiéry et al. 1999). Established RT-PCR methods (Nishizawa et al. 1994, Thiery et al. 1999) are based on specific nodaviral genomes and may be suboptimal for other nodaviruses. Our results indicate that there are mismatches between published primers and the genome of the Atlantic halibut nodavirus, necessitating a more specific RT-PCR assay. The problems associated with the specificity of RT-PCR detection of fish nodaviruses may be solved in the future if primers can be constructed that match highly conserved regions of the genomes, for instance if these are present within RNA1.

\section{SDS-PAGE and Western blot}

The recombinant proteins encoded by the T2 region reacted with antiserum raised against SJNNV but the protein derived from the Atlantic halibut nodavirus seemed to have a lower affinity to the antiserum. The positive reaction with the T2 expression protein in the Western blot experimentally confirms the putative ORF of the capsid protein gene within the RNA2. Current knowledge of the nodavirus genome does not permit the identification of genetic components relating to specific viral phenotypical features, but the existence of phenotypical differences between the 2 strains (SJ93Nag and AH93NorA) has been experimentally demonstrated in infection trials (Totland et al. 1999). The difference in staining intensity between the recombinant proteins of the 2 nodavirus strains is most likely due to differences in epitopes and may suggest the existence of serotypes within the Nodaviridae. Further studies are needed to determine whether differences between the capsid proteins of individual nodavirus strains are related to host range or other nodaviral phenotypical features.

Acknowledgements. The authors thank professor K. Muroga University of Hiroshima, Japan, and Research Director Brit K. Hjeltnes, Institute of Marine Research, Norway, for providing excellent working facilities. Takahiro Nagai, Ryoko Takano and Tove Boge Eriksen are thanked for excellent technical assistance. This study was supported by the Research Council of Norway

\section{LITERATURE CITED}

Arimoto M, Mushiake K, Mizuta Y, Nakai T, Muroga K, Fursawa I (1992) Detection of striped jack nervous necrosis virus (SJNNV) by enzyme-linked immunosorbent assay (ELISA). Fish Pathol 27:191-195

Comps M, Pepin JF, Bonami JR (1994) Purification and characterization of two fish encephalitis viruses (FEV) infecting Lates calcarifer and Dicentrarchus labrax. Aquaculture 123:1-10 
Delsert C, Morin N, Comps M (1997) A fish encephalitis virus that differs from other nodaviruses by its capsid protein processing. Arch Virol 142:2359-2371

Frerichs GN, Roger HD, Peric Z (1996) Cell culture isolation of piscine neuropathy nodavirus from juvenile sea bass, Dicentrarchus labrax. J Gen Virol 77:2067-2071

Grotmol S, Totland GK, Thorud K, Hjeltnes BK (1997) Vacuolating encephalopathy and retinopathy associated with a nodavirus-like agent: a probable cause of mass mortality of cultured larval and juvenile Atlantic halibut Hippoglossus hippoglossus. Dis Aquat Org 29:85-97

Grotmol S, Bergh Ø. Totland GK (1999) Transmission of viral encephalopathy and retinopathy (VER) to yolk-sac larvae of the Atlantic halibut Hippoglossus hippoglossus: occurrence of nodavirus in various organs and a possible route of infection. Dis Aquat Org 36:95-106

Laemmli UK (1970) Cleavage of structural proteins during the assembly of the head of bacteriophage T4. Nature 227 : $680-685$

Mori K, Nakai T, Muroga K, Arimoto M, Mushiake K, Furusawa I (1992) Properties of a new virus belonging to Nodaviridae found in larval striped jack (Pseudocaranx dentex) with nervous necrosis. Virology 187:368-371

Munday BL, Nakai T (1997) Special topic review: nodaviruses as pathogens in larval and juvenile marine finfish. World J Microbiol Biotechnol 13:375-381

Nakai T, Mori K, Arimoto M, Muroga K (1995) Neutralizing antibody production in striped jack immunized with a recombinant coat protein of striped jack nervous necrosis virus (SJNNV). In: European Association of Fish Pathologists 7 th International Conference 'Diseases of Fish and Shellfish', Palma de Mallorca, 10-15 September. Poster 179

Nishizawa T, Mori K, Nakai T, Furusawa I, Muroga K (1994) Polymerase chain reaction (PCR) amplification of RNA of striped jack nervous necrosis virus (SJNNV). Dis Aquat Org 18:103-107

Nishizawa T, Mori K, Furuhashi M, Nakai T, Furusawa I, Muroga K (1995) Comparison of the coat protein genes of five fish nodaviruses, the causative agents of viral nervous

Editorial responsibility: Jo-Ann Leong,

Corvallis, Oregon necrosis in marine fish. J Gen Virol 76:1563-1569

Nishizawa T, Muroga K, Arimoto M (1996) Failure of the polymerase chain reaction (PCR) method to detect striped jack nervous necrosis virus (SJNNV) in striped jack Pseudocaranx dentex selected as spawners. J Aquat Anim Health $8: 332-334$

Nishizawa T, Furuhashi M, Nagai T, Nakai T, Muroga K (1997) Genomic classification of fish nodaviruses by molecular phylogenetic analysis of the coat protein gene. Appl EnviIon Microbiol 63(4):1633-1636

Roderic DM (1996) TreeView, version 1.0. Division of Environmental and Evolutionary Biology, Institute of Biomedical and Life Sciences, University of Glasgow

Sambrook J, Fritsch EF, Maniatis T (1989) Molecular cloning, a laboratory manual. Cold Spring Harbor Laboratory Press, Cold Spring Harbor

Schneemann A, Reddy V, Johnson JE (1998) The structure and function of nodavirus particles: a paradigm for understanding chemical biology. Adv Vir Res 50:381-446

Sideris DC (1997) Cloning, expression and purification of the coat protein of encephalitis virus (DIEV) infecting Dicentrarchus labrax. Biochem Mol Biol Int 42:409-417

Thiéry R, Arnauld C, Delsert C (1999) Two isolates of the sea bass, Dicentrarchus labrax L., nervous necrosis virus with distinct genomes. J Fish Dis 22:201-207

Thompson JD, Higgins DG, Gibson TJ (1994) Clustral W: improving the sensitivity of progressive multiple sequence alignment through sequence weighting, positions-specific gap penalties and weight matrix choice. Nucleic Acids Res $22: 4673-4680$

Totland GK, Grotmol S, Morita Y, Nishioka T, Nakai T (1999) The pathogenicity of nodavirus strains from striped jack Pseudocaranx dentex and Atlantic halibut Hippoglossus hippoglossus studied by waterborne challenge of yolksac larvae of both teleost species. Dis Aquat Org 38: $169-175$

Towbin H, Staehelin T, Gordon J (1979) Electrophoretic transfer of proteins from polyacrylamide gels to nitrocellulose sheets: procedure and some applications. Proc Natl Acad Sci US 76:4350-4354

Submitted: June 15, 1999; Accepted: October 28, 1999

Proofs received from author(s): January 3,2000 